\title{
Nilotinib in patients with systemic mastocytosis: analysis of the phase 2, open-label, single-arm nilotinib registration study
}

\author{
Andreas Hochhaus ${ }^{1} \cdot$ Michele Baccarani $^{2} \cdot$ Francis J. Giles $^{3} \cdot$ Philipp D. le Coutre $^{4}$. \\ Martin C. Müller ${ }^{5}$ Andreas Reiter $^{5} \cdot$ Helene Santanastasio $^{6} \cdot$ Mimi Leung $^{6}$. \\ Steven Novick $^{6} \cdot$ Hagop M. Kantarjian ${ }^{7}$
}

Received: 5 May 2015 / Accepted: 9 May 2015 / Published online: 23 May 2015

(C) The Author(s) 2015. This article is published with open access at Springerlink.com

\begin{abstract}
Purpose Activating KIT mutations are part of the pathogenesis of systemic mastocytosis (SM). Nilotinib is a tyrosine kinase inhibitor that potently inhibits activated forms of KIT. This phase 2, open-label, single-arm study (CAMN107A2101; www.clinicaltrials.gov NCT00109707) evaluated nilotinib in patients with SM.

Methods Patients with SM [aggressive SM (ASM), indolent SM, or other] received nilotinib $400 \mathrm{mg}$ twice daily. C-findings were collected retrospectively to assess response using criteria proposed after trial initiation. Response was evaluated using improvements in laboratory findings (for all patients) and ASM response criteria (for the ASM subgroup).

Results In 61 patients enrolled, the median nilotinib exposure was 232 days (range 3-1274 days) with a median follow-up of 34.7 months. In patients with ASM $(n=37)$, the overall response rate was $21.6 \%$. In the eight
\end{abstract}

Andreas Hochhaus

andreas.hochhaus@med.uni-jena.de

1 Abteilung für Hämatologie und Internistische Onkologie, Universitätsklinikum Jena, Erlanger Allee 101, 07740 Jena, Germany

2 University of Bologna, Bologna, Italy

3 Northwestern Medicine Developmental Therapeutics Institute, Chicago, IL, USA

4 Charité - University of Medicine Berlin, Berlin, Germany

5 Medizinische Universitätsklinik, Medizinische Fakultät Mannheim der Universität Heidelberg, Mannheim, Germany

6 Novartis Pharmaceuticals Corporation, East Hanover, NJ, USA

7 The University of Texas, MD Anderson Cancer Center, Houston, TX, USA responders, all of whom had a KIT D816V mutation at any time, mast cell infiltration and tryptase level decreased by $70 \%$ and $29.8 \%$, respectively; absolute neutrophil count increased by $94.7 \%$. Laboratory parameters also improved in the non-ASM subgroups. Overall survival at 24 months was $81.2 \%$ (95\% CI 70.6-91.8\%) with median survival not yet reached. New or worsening grade $3 / 4$ hematologic adverse events (AEs) included thrombocytopenia (10.3\%), anemia $(10.0 \%)$, and neutropenia $(6.9 \%)$. The most common grade $3 / 4$ nonhematologic drug-related AEs were diarrhea $(6.6 \%)$ and headache $(4.9 \%)$. Eleven patients (9 with ASM, 2 with MCL) died, 10 due to progressive disease; 7 deaths occurred $\geq 28$ days after treatment discontinuation.

Conclusions Nilotinib $400 \mathrm{mg}$ twice daily was effective in some patients with SM, including patients with mutated KIT D816V.

Keywords Nilotinib - Tyrosine kinase inhibitor . Systemic mastocytosis - KIT D816V · Aggressive systemic mastocytosis $\cdot$ Indolent systemic mastocytosis

\section{Introduction}

Systemic mastocytosis (SM) is a myeloproliferative neoplasm characterized by the proliferation and activation of mast cells in various organs, including the skin, liver, spleen, and hematopoietic tissues, eventually resulting in impaired organ function (Valent et al. 2003). The clinical course in SM is heterogeneous and ranges from asymptomatic with a normal life expectancy to highly aggressive with decreased life expectancy (Quintas-Cardama et al. 2011). SM is rare; the annual incidence of new cases is 0.3 per 100,000 (Woodward 2003). The median overall survival is approximately 63 months overall, 198 months for 
patients with indolent SM (ISM), 24 months for patients with aggressive SM (ASM), and 2 months for patients with mast cell leukemia (MCL) (Lim et al. 2009b; Fuller 2012).

SM is classified based on the abnormal morphology, immunophenotype, and molecular characteristics of mast cells. The diagnostic algorithm for SM includes evaluating bone marrow by immunostaining for the presence of tryptase and/or KIT and immunophenotyping mast cells for expression of CD25 and/or CD2. Serum tryptase level and the presence of the KIT D816V mutation in blood or bone marrow are also evaluated. SM is then categorized as ISM ( 2 or more B-findings), ASM ( 1 or more C-findings), or MCL (at least $20 \%$ mast cells on bone marrow aspirate smear) (Pardanani 2015; Horny et al. 2008).

There is no accepted standard therapy for patients with SM. Patients generally receive treatments intended to manage symptoms and improve quality of life, such as antihistamines for the relief of pruritus and flushing, proton pump inhibitors to treat gastrointestinal symptoms, or corticosteroids and/or analgesics for mitigating bone pain and other symptoms (Andersen et al. 2012; Valent et al. 2010; Pardanani 2015). Patients with advanced SM may receive treatment with interferon (IFN)- $\alpha$ or cladribine; these treatments also decrease symptoms but may not substantially reduce mast cell burden (Verstovsek 2013). Tyrosine kinase inhibitors (TKIs), such as imatinib, have demonstrated modest effects in SM, although primary resistance is common in patients with the KIT D816V mutation (Lim et al. 2009a; Pardanani 2012; Valent et al. 2010).

As many as $93 \%$ of SM cases may harbor an activating D816V mutation in the catalytic domain of KIT (GarciaMontero et al. 2006; Quintas-Cardama et al. 2011; Akin and Metcalfe 2004), a receptor tyrosine kinase expressed on the surface of mature mast cells and mast cell precursors (Lammie et al. 1994; Valent et al. 2003). The KIT D816V mutation induces downstream signaling that is independent of the KIT ligand stem cell factor (Furitsu et al. 1993) and is mediated through the signal transducer and activator of transcription 5 (STAT5) and phosphoinositol-3-kinase (PI3K) pathways (Harir et al. 2008). Constitutive KIT activation results in increased mast cell accumulation in the bone marrow and more aggressive disease (Valent et al. 2003; Lim et al. 2009b; Verstovsek 2013). The presence of the KIT D816V mutation is one of four minor criteria for the diagnosis of SM (Valent et al. 2003), and KIT D816V allele burden can be used to monitor residual disease in patients with SM (Erben et al. 2014). Additional KIT mutations as well as KIT-independent pathways (e.g., Lyn and Btk) have recently been implicated in the pathogenesis of SM (Gleixner et al. 2011; Schwaab et al. 2013; Orfao et al. 2007).

The TKI nilotinib was rationally designed to inhibit mutant forms of the BCR-ABL protein that display resistance to the TKI imatinib in patients with chronic myeloid leukemia (CML); both imatinib and nilotinib are approved for the treatment of CML. Nilotinib is also active against the KIT kinase in vitro (Weisberg et al. 2005; Manley et al. 2010). Recent data from a multicenter, phase 2 , open-label registration trial demonstrated that nilotinib $400 \mathrm{mg}$ twice daily continued to be safe and effective in patients with CML in chronic phase (Giles et al. 2013), accelerated phase (le Coutre et al. 2012), and blast crisis (Giles et al. 2012) who were resistant to or intolerant of prior therapies. Based on promising results from the first data analysis (Hochhaus et al. 2006), we evaluated the efficacy and safety of nilotinib $400 \mathrm{mg}$ twice daily in patients with SM (with or without the D816V mutation) enrolled in the phase 2 nilotinib registration trial (CAMN107A2101, registered at www.clinicaltrials.gov as NCT00109707).

\section{Materials and methods}

\section{Patient population}

Enrollment criteria for the phase 2, multicenter 2101 trial have been previously described (H. M. Kantarjian et al. 2007). Briefly, adult patients with hematologic malignancies were recruited into 6 parallel treatment arms. Patients who met the standard disease criteria for SM (at least 1 major and 1 minor or 3 minor criteria for SM) (Valent et al. 2003) and needed treatment were recruited into the SM arm of the study and were assessed for efficacy according to a Simon two-stage minimax design (Simon 1989). The major criterion for SM is the presence of multifocal clusters of mast cells in the bone marrow. The minor criteria are the presence of spindle-shaped mast cells in the marrow, elevated serum tryptase levels, abnormal expression of $\mathrm{CD} 2$ or CD25, and the presence of the KIT D816V mutation (Valent et al. 2001). Key inclusion criteria included World Health Organization (WHO) performance status $\leq 2$. Exclusion criteria included disease infiltration into the central nervous system and impaired cardiac function (including a left ventricular ejection fraction $<45 \%$, congenital long QT syndrome, or QTc $>450 \mathrm{~ms}$ ).

Recruitment occurred between June 9, 2005, and March 31, 2006. Data on the significance of improvements in clinical findings (C-findings) as a measure of treatment response and clear definitions of the various types of SM were published after initiation of the study (Gotlib et al. 2013; Horny et al. 2008). To incorporate these data into the study, C-findings were collected, and patients were categorized as having ASM, ISM, or other SM subtype retrospectively based on WHO criteria for these SM subtypes (Horny et al. 2008). Per the WHO criteria, patients meeting $\mathrm{SM}$ criteria who had one or more $\mathrm{C}$-findings were classified 
as having ASM as long as the criteria for MCL were not met.

Informed consent was obtained from all patients according to institutional guidelines. The study was conducted in accordance with the Declaration of Helsinki; the protocol and all amendments were reviewed and approved by the ethics board or institutional review board at each participating trial center.

\section{Dosing}

Nilotinib $400 \mathrm{mg}$ twice daily was selected as the study dose based on safety and tolerability and pharmacokinetic and preliminary efficacy data from the phase 1 portion of this study (H. Kantarjian et al. 2006). One treatment cycle consisted of 28 days of continuous dosing with nilotinib $400 \mathrm{mg}$ twice daily. Patients remained on nilotinib treatment until disease progression or unacceptable toxicity that precluded additional therapy. Patients responding to therapy were allowed to enter an extension study after 24 months of treatment and continue receiving drug.

Dose modifications, including dose reductions and dose interruptions, were allowed for patients who developed intolerance to nilotinib. Patients with treatment interruptions longer than 21 days were discontinued from the study, except those with hematologic toxicity, in whom interruptions were permitted for up to 42 days. Patients discontinuing due to adverse events (AEs) were monitored until resolution or stabilization of the AE. All patients were monitored for AEs for 28 days after the final dose of nilotinib.

\section{Study objectives}

The primary efficacy endpoint was the overall response rate (ORR), defined as the proportion of patients with a minor response or better lasting a minimum of 4 weeks (Valent et al. 2003). Response was evaluated using improvements in laboratory findings (for all patients) and ASM response criteria (for the ASM subgroup). For patients with ASM, response evaluations were based on findings in bone marrow, peripheral blood, and extramedullary sites of disease and improvements in C-findings (Valent et al. 2007). $\mathrm{C}$-findings were defined as hematologic abnormalities [absolute neutrophil count (ANC) $<1.0 \times 10^{9} / \mathrm{L}$, hemoglobin level $<10 \mathrm{~g} / \mathrm{dL}$, or platelet count $\left.<100 \times 10^{9} / \mathrm{L}\right]$, hepatomegaly with ascites and impaired liver function, portal hypertension, palpable splenomegaly with hypersplenism, malabsorption with hypoalbuminemia and/or weight loss, and skeletal lesions (such as large-sized osteolyses and/or severe osteoporosis with pathological fracture). The definitions of complete or incomplete remission and pure clinical response included complete resolution of 1 $\mathrm{C}$-finding and no progression in other $\mathrm{C}$-findings. Complete remission also required disappearance of organomegaly, decrease of serum tryptase level to $<20 \mathrm{ng} / \mathrm{mL}$, and loss of all mast cell infiltrates in affected organs. Incomplete remission required $>50 \%$ decrease in serum tryptase level and/or a decrease in mast cell infiltrates and/or visible reduction of organomegaly. Pure clinical response involved no response in mast cell infiltrates, serum tryptase level, or organomegaly. Good partial response was defined as $>50 \%$ regression in $\geq 1 \mathrm{C}$-findings and no progression in other $\mathrm{C}$-findings. Minor response was defined as $\leq 50 \%$ regression of $\geq 1 \mathrm{C}$-findings and no progression in other $\mathrm{C}$-findings. Stable disease was defined by $\mathrm{C}$-finding parameters falling within a constant range. Progressive disease was defined as $\geq 1$ C-finding with progression.

Secondary efficacy endpoints included overall survival, which was estimated using the Kaplan-Meier method. The analysis of overall survival included all deaths occurring during treatment or after discontinuation of study drug. Assessment of KIT mutation status was performed by Sanger sequencing after polymerase chain reaction (PCR) amplification, and FIP1L1-PDGFRA translocation status was determined by nested reverse-transcriptase PCR at baseline and/or at various time points throughout the study. The ORR stratified by KIT D816V mutation status at baseline or at any time was assessed.

Laboratory parameters were assessed to help characterize the quality of response in responders in the ASM subgroup and in all patients with other SM subtypes. For each laboratory parameter, values were recorded at baseline and the time of best response. The "best value" was the lowest level of tryptase and mast cell burden and the highest level for other parameters. The median baseline and best value were calculated for the responder population. The difference between these median values was then used to determine the percentage improvement in each parameter.

Toxicity was assessed using the National Cancer Institute Common Terminology Criteria for Adverse Events (NCI CTCAE) version 3.0 (National Cancer Institute 2006). AEs, serious AEs (SAEs), and hematologic and nonhematologic laboratory abnormalities were assessed.

\section{Results}

\section{Patient characteristics}

Baseline demographic and disease characteristics of the 61 patients enrolled in the SM arm of the 2101 study are listed in Table 1. Patients were retrospectively assigned to SM subgroups based on WHO 2008 criteria (Tefferi and Vardiman 2008). The patient population was heterogeneous. Most patients had ASM $[n=37(60.7 \%)]$ or ISM $[n=19$ $(31.1 \%)$ ]; of the 5 remaining patients, 3 had MCL, 1 had 
Table 1 Characteristics of all patients and responders

\begin{tabular}{|c|c|c|c|c|c|}
\hline & \multirow{2}{*}{$\begin{array}{l}\text { Total } \\
\text { All patients } \\
(N=61)\end{array}$} & \multicolumn{2}{|l|}{ ASM } & \multirow{2}{*}{$\begin{array}{l}\text { ISM } \\
\text { All patients } \\
(n=19)\end{array}$} & \multirow{2}{*}{$\begin{array}{l}\text { Other }^{\mathrm{a}} \\
\text { All patients } \\
(n=5)\end{array}$} \\
\hline & & $\begin{array}{l}\text { All patients } \\
(n=37)\end{array}$ & $\begin{array}{l}\text { Responders } \\
(n=8)\end{array}$ & & \\
\hline \multicolumn{6}{|l|}{ Characteristics at baseline } \\
\hline Median age (range, years) & $52(29-79)$ & $49(29-79)$ & $55(41-79)$ & $50(33-78)$ & $66(52-67)$ \\
\hline Male, $n(\%)$ & $34(55.7)$ & $21(56.8)$ & $3(37.5)$ & $11(57.9)$ & $2(40.0)$ \\
\hline \multicolumn{6}{|l|}{ Entry criteria for SM, $n(\%)$} \\
\hline Major + 1 minor criteria & $49(80.3)$ & $29(78.4)$ & $8(100)$ & $16(84.2)$ & $4(80.0)$ \\
\hline Three minor criteria & $11(18.0)$ & $8(21.6)$ & 0 & $2(10.5)$ & $1(20)$ \\
\hline Other $^{\mathrm{b}}$ & $1(1.6)$ & 0 & 0 & $1(5.3)$ & 0 \\
\hline No prior treatment, $n(\%)$ & $29(47.5)$ & $15(40.5)$ & $1(12.5)$ & $10(52.6)$ & $4(80.0)$ \\
\hline \multicolumn{6}{|l|}{ WHO performance status, $n(\%)$} \\
\hline Grade 0 & $26(42.6)$ & $15(40.5)$ & $1(12.5)$ & $9(47.4)$ & $2(40.0)$ \\
\hline Grade 1 & $25(41.0)$ & $14(37.8)$ & $6(75.0)$ & $9(47.7)$ & $2(40.0)$ \\
\hline Grade 2 & $8(13.1)$ & $6(16.2)$ & 0 & $1(5.3)$ & $1(20.0)$ \\
\hline Grade $>2$ & $1(1.6)$ & $1(2.7)$ & $1(12.5)$ & 0 & 0 \\
\hline Missing & $1(1.6)$ & $1(2.7)$ & 0 & 0 & 0 \\
\hline $\begin{array}{l}\text { Median time since diagnosis of SM } \\
\text { (range, months) }\end{array}$ & $25.9(1.2-287.3)$ & $25.9(1.2-287.3)$ & $34.5(9.2-84.8)$ & $27.4(1.6-123.4)$ & $8.34(3.1-77.6)$ \\
\hline \multicolumn{6}{|l|}{ Time since SM diagnosis, $n(\%)$} \\
\hline$<6$ months & $13(21.3)$ & $10(27.0)$ & 0 & $2(10.5)$ & $1(20.0)$ \\
\hline 6 months to $<1$ year & $8(13.1)$ & $3(8.1)$ & $1(12.5)$ & $3(15.8)$ & $2(40.0)$ \\
\hline 1 to $<2$ years & $8(13.1)$ & $5(13.5)$ & $1(12.5)$ & $3(15.8)$ & 0 \\
\hline 2 to $<5$ years & $13(21.3)$ & $9(24.3)$ & $3(37.5)$ & $3(15.8)$ & $1(20.0)$ \\
\hline$\geq 5$ years & $19(31.1)$ & $10(27.0)$ & $3(37.5)$ & $8(42.1)$ & $1(20.0)$ \\
\hline \multicolumn{6}{|l|}{ KIT D816V mutation status, $n(\%)$} \\
\hline \multicolumn{6}{|l|}{ At baseline ${ }^{c}$} \\
\hline Yes & $36(59.0)$ & $22(59.5)$ & $6(75.0)$ & $10(52.6)$ & $4(80.0)$ \\
\hline No & $5(8.2)$ & $2(5.4)$ & 0 & $3(15.8)$ & 0 \\
\hline Missing & $20(32.8)$ & $13(35.1)$ & $2(25.0)$ & $6(31.6)$ & $1(20.0)$ \\
\hline \multicolumn{6}{|l|}{ At any time } \\
\hline Yes & $48(78.7)$ & $29(78.4)$ & $8(100)$ & $15(78.9)$ & $4(80.0)$ \\
\hline No & $13(21.3)$ & $8(21.6)$ & 0 & $4(21.1)$ & $1(20.0)$ \\
\hline Missing & 0 & 0 & 0 & 0 & 0 \\
\hline \multicolumn{6}{|l|}{ Laboratory values at baseline } \\
\hline Tryptase level, ng/mL & $(n=54)$ & $(n=33)$ & $(n=7)$ & $(n=16)$ & $(n=5)$ \\
\hline$<20$ & $4(7.4)$ & $3(9.1)$ & $1(14.3)$ & $1(6.3)$ & 0 \\
\hline $20-100$ & $18(33.3)$ & $8(24.2)$ & $1(14.3)$ & $8(50.0)$ & $2(40.0)$ \\
\hline$>100-200$ & $19(35.2)$ & $13(39.4)$ & $2(28.6)$ & $5(31.3)$ & $1(20.0)$ \\
\hline$>200$ & $13(24.1)$ & $9(27.3)$ & $3(42.9)$ & $2(12.5)$ & $2(40.0)$ \\
\hline \multicolumn{6}{|l|}{ Hemoglobin level (g/dL) } \\
\hline$<10$ & $7(11.5)$ & 7 (18.9) & $2(25.0)$ & 0 & 0 \\
\hline $10-15$ & $47(77.0)$ & $26(70.3)$ & $6(75.0)$ & $16(84.2)$ & $5(100)$ \\
\hline$>15$ & $7(11.5)$ & $4(10.8)$ & 0 & $3(15.8)$ & 0 \\
\hline \multicolumn{6}{|l|}{ Albumin level (g/dL) } \\
\hline$<3.4$ & $7(11.5)$ & $5(13.5)$ & $2(25.0)$ & 0 & $2(40.0)$ \\
\hline $3.4-5.4$ & $54(88.5)$ & $32(86.5)$ & $6(75.0)$ & $19(100)$ & $3(60.0)$ \\
\hline$>5.4$ & 0 & 0 & 0 & 0 & 0 \\
\hline
\end{tabular}


Table 1 continued

\begin{tabular}{|c|c|c|c|c|c|}
\hline & \multirow{2}{*}{$\begin{array}{l}\text { Total } \\
\text { All patients } \\
(N=61)\end{array}$} & \multicolumn{2}{|l|}{ ASM } & \multirow{2}{*}{$\begin{array}{l}\text { ISM } \\
\text { All patients } \\
(n=19)\end{array}$} & \multirow{2}{*}{$\begin{array}{l}\text { Other }^{\mathrm{a}} \\
\text { All patients } \\
(n=5)\end{array}$} \\
\hline & & $\begin{array}{l}\text { All patients } \\
(n=37)\end{array}$ & $\begin{array}{l}\text { Responders } \\
(n=8)\end{array}$ & & \\
\hline \multicolumn{6}{|l|}{$\operatorname{ANC}\left(\times 10^{9} / \mathrm{L}\right)$} \\
\hline$<2$ & $4(6.6)$ & $3(8.1)$ & $1(12.5)$ & 0 & $1(20.0)$ \\
\hline $2-7$ & $47(77.0)$ & $28(75.7)$ & $5(62.5)$ & $16(84.2)$ & $3(60.0)$ \\
\hline$>7$ & $10(16.4)$ & $6(16.2)$ & $2(25.0)$ & $3(15.8)$ & $1(20.0)$ \\
\hline \multicolumn{6}{|l|}{ Platelet count $\left(\times 10^{9} / \mathrm{L}\right)$} \\
\hline$<100$ & $9(14.8)$ & $8(21.6)$ & $2(25.0)$ & 0 & $1(20.0)$ \\
\hline $100-400$ & $50(82.0)$ & $27(73.0)$ & $5(62.5)$ & $19(100)$ & $4(80.0)$ \\
\hline$>400$ & $2(3.3)$ & $2(5.4)$ & $1(12.5)$ & 0 & 0 \\
\hline Bone marrow mast cell infiltration (\%) & $(n=55)$ & $(n=34)$ & $(n=7)$ & $(n=17)$ & $(n=4)$ \\
\hline$<10$ & $24(43.6)$ & $16(47.1)$ & $4(57.1)$ & $8(47.1)$ & 0 \\
\hline $10-20$ & $15(27.3)$ & $9(26.5)$ & $2(28.6)$ & $5(29.4)$ & $1(25.0)$ \\
\hline$>20-30$ & $5(9.1)$ & $2(5.9)$ & $1(14.3)$ & $3(17.6)$ & 0 \\
\hline$>30$ & $11(20.0)$ & 7 (20.6) & 0 & $1(5.9)$ & $3(75.0)$ \\
\hline \multicolumn{6}{|l|}{ Symptoms at baseline, $n(\%)^{\mathrm{d}}$} \\
\hline Urticaria & $20(32.8)$ & $11(29.7)$ & $2(25.0)$ & $8(42.1)$ & $1(20.0)$ \\
\hline Cutaneous symptoms & $36(59.0)$ & $21(56.8)$ & $5(62.5)$ & $13(68.4)$ & $2(40.0)$ \\
\hline Constitutional symptoms & $33(54.1)$ & $22(59.5)$ & $3(37.5)$ & $8(42.1)$ & $3(60.0)$ \\
\hline Mediator-related symptoms & $31(50.8)$ & $20(54.1)$ & $5(62.5)$ & $9(47.4)$ & $3(60.0)$ \\
\hline
\end{tabular}

$A M L$ acute myeloid leukemia, $A H N M D$ associated clonal hematologic non-mast cell lineage disease, ANC absolute neutrophil count, $A S M$ aggressive systemic mastocytosis, ISM indolent systemic mastocytosis, $M C L$ mast cell leukemia, $S M$ systemic mastocytosis, WHO World Health Organization

a Includes 3 patients with MCL, 1 patient with SM-AHNMD (responder, incomplete remission), and 1 patient with SM-AML

b Patient withdrew consent and was discontinued from the trial on study day 34

${ }^{c}$ Based on bone marrow or peripheral blood samples taken at baseline

d Symptoms were categorized as follows: constitutional symptoms—-weight loss, fever, chills, night sweats, fatigue, lethargy, nausea, vomiting, and diarrhea; cutaneous symptoms - pruritus, flushing, urticaria, angioedema, erythema, atopic dermatitis, rashes, systemic lupus erythematosus, herpes zoster, and skin mastocytosis; mediator-related symptoms - headache, dizziness/lightheadedness, migraine, vertigo, and syncope/presyncope

SM-acute myeloid leukemia (AML), and 1 had SM with an associated clonal hematologic non-mast cell lineage disease (AHNMD). At study entry, 49 patients $(80.3 \%)$ met 1 major and 1 minor disease criteria for SM; 11 patients $(18.0 \%)$ met 3 minor criteria for SM; and 1 patient (1.6\%) had a major protocol violation, defined as entering the study but not meeting the predefined SM disease group classification. In the ASM group ( $n=37)$, C-findings were as follows: 15 patients had skeletal involvement only; 11 patients had cytopenias only; 3 patients had hepatosplenomegaly only; 3 patients had skeletal lesions accompanied by hepatosplenomegaly; and 5 patients had malabsorption, skeletal lesions, and hepatosplenomegaly. The median time since first diagnosis of SM was 25.9 months (range 1.2-287.3 months). The median patient age was 52 years (range 29-79 years). The median time since diagnosis was similar in patients with ASM and those with ISM (25.9 vs 27.4 months, respectively). At baseline, 36 patients $(59.0 \%)$ had a KIT D816V mutation, and 5 patients (8.2 \%) had no KIT mutation; in 20 patients (32.8\%), KIT mutation analysis was missing. All patients had at least 1 sample evaluated for KIT mutation status at any point during the study. Of the 25 patients with no or missing mutation data at baseline, $12(48.0 \%)$ subsequently tested positive for KIT D816V. Using data obtained at any point during the study, 48 patients $(78.7 \%$ ) had a KIT D816V mutation, and 13 patients $(21.3 \%)$ did not; no patients had a D816Y mutation. All of the 53 patients tested for the FIP1L1PDGFR $\alpha$ fusion at any time during the study had a negative result.

Baseline characteristics of these retrospectively determined subgroups reflected differences in overall disease status. For example, the proportion of patients with WHO performance status of $\geq 2$ was higher in the ASM group $(18.9 \%)$ than in the ISM group $(5.3 \%)$. Fewer patients in the ASM group had no prior treatment for SM (40.5 vs $52.6 \%$ in the ISM group). Baseline tryptase levels were generally higher in the ASM group $(27.3 \%$ of patients had 
levels $>200 \mathrm{ng} / \mathrm{mL}$ at baseline vs $12.5 \%$ of patients in the ISM group). Anemia (hemoglobin level $<10 \mathrm{~g} / \mathrm{dL}$ ), neutropenia (ANC $<2 \times 10^{9} / \mathrm{L}$ ), and thrombocytopenia (platelet count $<100 \times 10^{9} / \mathrm{L}$ ) were all more common in the ASM group than the ISM group (18.9 vs $0 \%, 8.1$ vs $0 \%$, and 21.6 vs $0 \%$, respectively). The proportion of patients with bone marrow mast cell infiltration $>30 \%$ was also greater in the ASM group (20.6\%) than in the ISM group (5.9 \%). Constitutional and mediator-related symptoms were more common in patients with ASM than in those with ISM (59.5 vs 42.1 and 54.1 vs $47.4 \%$, respectively), whereas urticarial and cutaneous symptoms were less common in the ASM group than the ISM group (29.7 vs 42.1 and 56.8 vs $68.4 \%$, respectively).

\section{Patient disposition and drug exposure}

At the time of data cutoff (January 19, 2009), 8 patients had entered the extension study, and 53 patients had discontinued treatment (Table 2). The most common reason for discontinuation was AEs $[n=18(29.5 \%)]$. Diarrhea, fatigue, and pain in extremity (3.3\% each) were the AEs most frequently leading to discontinuation. Eleven patients $(18.0 \%)$ experienced grade $3 / 4$ AEs leading to discontinuation. Each grade $3 / 4 \mathrm{AE}$ occurred in only 1 patient. Eleven patients $(18 \%)$ had disease progression that led to discontinuation.

The median total daily dose of nilotinib received was close to the planned total daily dose of $800 \mathrm{mg}$ [787.6 mg

Table 2 Patient disposition

\begin{tabular}{|c|c|}
\hline & $n(\%)$ \\
\hline Total patients treated & $61(100)$ \\
\hline Entered extension study ${ }^{a}$ & $8(13.1)$ \\
\hline Discontinued core treatment & $53(86.9)$ \\
\hline Adverse event(s) & $18(29.5)$ \\
\hline Withdrew consent & $15(24.6)$ \\
\hline Disease progression & $11(18.0)$ \\
\hline Administrative problems ${ }^{\mathrm{b}}$ & $5(8.2)$ \\
\hline Abnormal test procedure result(s) & $1(1.6)$ \\
\hline Protocol violation & $1(1.6)$ \\
\hline Lost to follow-up & $1(1.6)$ \\
\hline Death $^{\mathrm{c}}$ & $1(1.6)$ \\
\hline
\end{tabular}

a Enrolled in the ongoing extension portion of the study at the time of data cutoff

b One patient underwent dose interruption for thrombocytopenia, which did not resolve within the time period specified by the protocol; the patient was therefore removed from the study by the sponsor. The other 4 patients were discontinued due to unsatisfactory response (all had stable disease)

c Only includes patients for whom death was cited as the primary reason for discontinuation of study treatment (range 318.9-953.5 mg)]. Median treatment duration was 232 days (range 3-1274 days). One-third of patients $(32.8 \%)$ were treated with nilotinib for a minimum of 12 months, and $18.0 \%$ received nilotinib for $\geq 24$ months. Nearly half of all patients had a nilotinib dose reduction $[n=29(47.5 \%)]$ and/or interruption $[n=30(49.2 \%)]$. The most common AEs requiring dose adjustment or interruption were nausea $(16.4 \%)$, diarrhea $(14.8 \%)$, vomiting $(13.1 \%)$, and fatigue $(6.6 \%)$. Dose interruptions lasted a median of 13.5 days (range 2-47 days). Interruptions constituted a median of $5.1 \%$ of total dosing days (range $0.2-42 \%)$.

\section{Efficacy and characteristics of responders in the ASM subgroup}

In the ASM subgroup, a minor response or better was achieved by 8 patients $(21.6 \%)$ receiving nilotinib $400 \mathrm{mg}$ twice daily, all of whom had a KIT D816V mutation at any time during the study (Table 3). Incomplete remission and pure clinical response were each achieved by 1 patient, while good partial response and minor response were each achieved by 3 patients $(8.1 \%)$. Stable disease was observed in 16 patients $(43.2 \%)$, and 3 patients $(8.1 \%)$ had disease progression as their best response. Ten patients were not evaluable for response, in part because some patients did not have baseline $\mathrm{C}$-finding data, which were collected retrospectively after response criteria for ASM became available (Gotlib et al. 2013).

In patients with ASM, responses were evaluated based on baseline KIT D816V mutation status (Table 3). Of 22 patients with mutated KIT D816V at baseline, 6 (27.3\%) achieved an overall response to treatment, including 1 pure clinical response (4.5\%), 2 good partial responses (9.1\%), and 3 minor responses (13.6\%). Nine patients with a baseline KIT D816V mutation (40.9\%) had stable disease, and 1 patient $(4.5 \%)$ had disease progression. Of 15 patients with no baseline mutation or missing KIT D816V status, 2 $(13.3 \%)$ had an overall response to treatment [including 1 incomplete remission $(6.7 \%)$ and 1 good partial response $(6.7 \%)$ ], $46.7 \%$ had stable disease, and $13.3 \%$ had disease progression as their best response. However, 7 of 15 patients with no or missing KIT mutation status at baseline tested positive for a $\mathrm{D} 816 \mathrm{~V}$ mutation in subsequent analyses.

The baseline characteristics of ASM responders were largely similar to those of the total ASM population, but some differences were observed (Table 1). For instance, all responders had the major criterion for SM (vs $78.4 \%$ of all patients). Further, the proportion of patients with constitutional symptoms was lower in responders than in the total ASM population (37.5 vs $59.5 \%$ ), and the proportion of patients with bone marrow mast cell infiltration $<10 \%$ was higher in responders (62.5 vs $47.1 \%)$. The median 
Table 3 Best responses in the ASM subgroup and by KIT D816V mutation status at baseline or at any time during the study

\begin{tabular}{|c|c|c|c|c|c|}
\hline & \multirow[t]{2}{*}{$\begin{array}{l}\text { ASM } \\
(n=37)\end{array}$} & \multicolumn{2}{|c|}{ KIT D816V mutation at baseline } & \multicolumn{2}{|c|}{$\begin{array}{l}\text { KIT D } 816 \mathrm{~V} \text { mutation at } \\
\text { any time }\end{array}$} \\
\hline & & Yes $(n=22)$ & No/missing $(n=15)$ & $\operatorname{Yes}^{\mathrm{a}}(n=29)$ & No $(n=8)$ \\
\hline \multicolumn{6}{|l|}{ Response $(95 \% \mathrm{CI}), n(\%)$} \\
\hline Overall response & $8(21.6)$ & $6(27.3)$ & $2(13.3)$ & $8(27.6)$ & 0 \\
\hline Complete remission & 0 & 0 & 0 & 0 & 0 \\
\hline Incomplete remission & $1(2.7)$ & 0 & $1(6.7)$ & $1(3.4)$ & 0 \\
\hline Pure clinical response & $1(2.7)$ & $1(4.5)$ & 0 & $1(3.4)$ & 0 \\
\hline Good partial response & $3(8.1)$ & $2(9.1)$ & $1(6.7)$ & $3(10.3)$ & 0 \\
\hline Minor response & $3(8.1)$ & $3(13.6)$ & 0 & $3(10.3)$ & 0 \\
\hline Absence of response & $29(78.4)$ & $16(72.7)$ & $13(86.7)$ & $21(72.4)$ & $8(100)$ \\
\hline Stable disease & $16(43.2)$ & $9(40.9)$ & $7(46.7)$ & $14(48.3)$ & $2(25.0)$ \\
\hline Progression & $3(8.1)$ & $1(4.5)$ & $2(13.3)$ & $1(3.4)$ & $2(25.0)$ \\
\hline Not evaluable & $10(27.0)$ & $6(27.3)$ & $4(26.7)$ & $6(20.7)$ & $4(50.0)$ \\
\hline
\end{tabular}

ASM aggressive systemic mastocytosis

${ }^{\text {a }}$ Includes 7 patients with ASM with no/missing mutation data at baseline time since SM diagnosis was longer for responders than for all patients (34.5 vs 25.9 months), and presence of the KIT D816V mutation at any time was more common in responders $(100 \%)$ compared with the total ASM population $(78.4 \%)$.

\section{Description of response as measured by changes in laboratory parameters}

In responders in the ASM subgroup, the parameter with the highest degree of change was ANC; median best increase from baseline was $94.7 \%$ (Fig. 1). Furthermore, when best values were compared with baseline values, the proportion of mast cells found in bone marrow decreased $70.0 \%$. Moderate change was seen in platelet counts $(43.5 \%$ increase) and tryptase levels (29.8\% decrease). There was little change in hemoglobin and albumin levels during the study (increases of 11.5 and $15.1 \%$, respectively).

Because the ASM criteria for response cannot be used in patients with other SM subtypes, patients in other subgroups were evaluated based on changes in laboratory parameters. In the ISM subgroup ( $n=17$ evaluable at baseline), the proportion of mast cells found in the bone marrow decreased $80 \%$, and ANC decreased by $64.6 \%$ (Fig. 2). Platelet counts increased by $19.5 \%$. As in the ASM subgroup, hemoglobin and albumin levels showed minimal change during the study (increases of 4.3 and $4.5 \%$, respectively). The median tryptase level in the ISM group increased by $22.6 \%$; however, the interquartile range of tryptase levels at baseline and best value during the study showed a trend for decreasing tryptase levels.

Because patients in the "other" subgroup had different SM designations, patient laboratory values were evaluated individually rather than as a group (Fig. 3). All of these patients, except 1 patient with MCL (denoted as MCL-3 in the figure), had a KIT D816V mutation at any time. In general, most patients in the "other" subgroup experienced improvements in albumin and neutrophil levels and platelet counts. The patient with SM-AML experienced a decrease in hemoglobin, while all other patients experienced an increase in hemoglobin during the study. Because of missing values, trends in mast cell infiltration and tryptase level in this population could not be determined.

\section{Survival}

During the study, 11 deaths occurred: 9 in the ASM subgroup and 2 in the "other" subgroup (both patients with MCL). Four deaths occurred during treatment or within 28 days of study drug discontinuation, while 7 deaths occurred during long-term follow-up. Ten deaths were due to disease progression, and 1 cause of death was listed as dyspnea and weakness. Of patients with KIT D816V mutations at baseline $(n=36)$ or at any time $(n=48), 5$ deaths were reported. The rate of overall survival at 24 months was $81.2 \%$ (95\% CI 70.6-91.8\%), with the median overall survival not yet reached after a median of 34.7 months of follow-up (Fig. 4).

\section{Safety}

All patients reported at least $1 \mathrm{AE}$, which was not unexpected given the severe nature of the underlying disease. The most frequent study drug-related AEs included nausea $(39.3 \%)$, headache $(32.8 \%)$, fatigue $(29.5 \%)$, diarrhea ( $27.9 \%$ ), vomiting (26.2\%), and pruritus ( $24.6 \%$; Table 4 ). Gastrointestinal and skin toxicities were consistent with the 


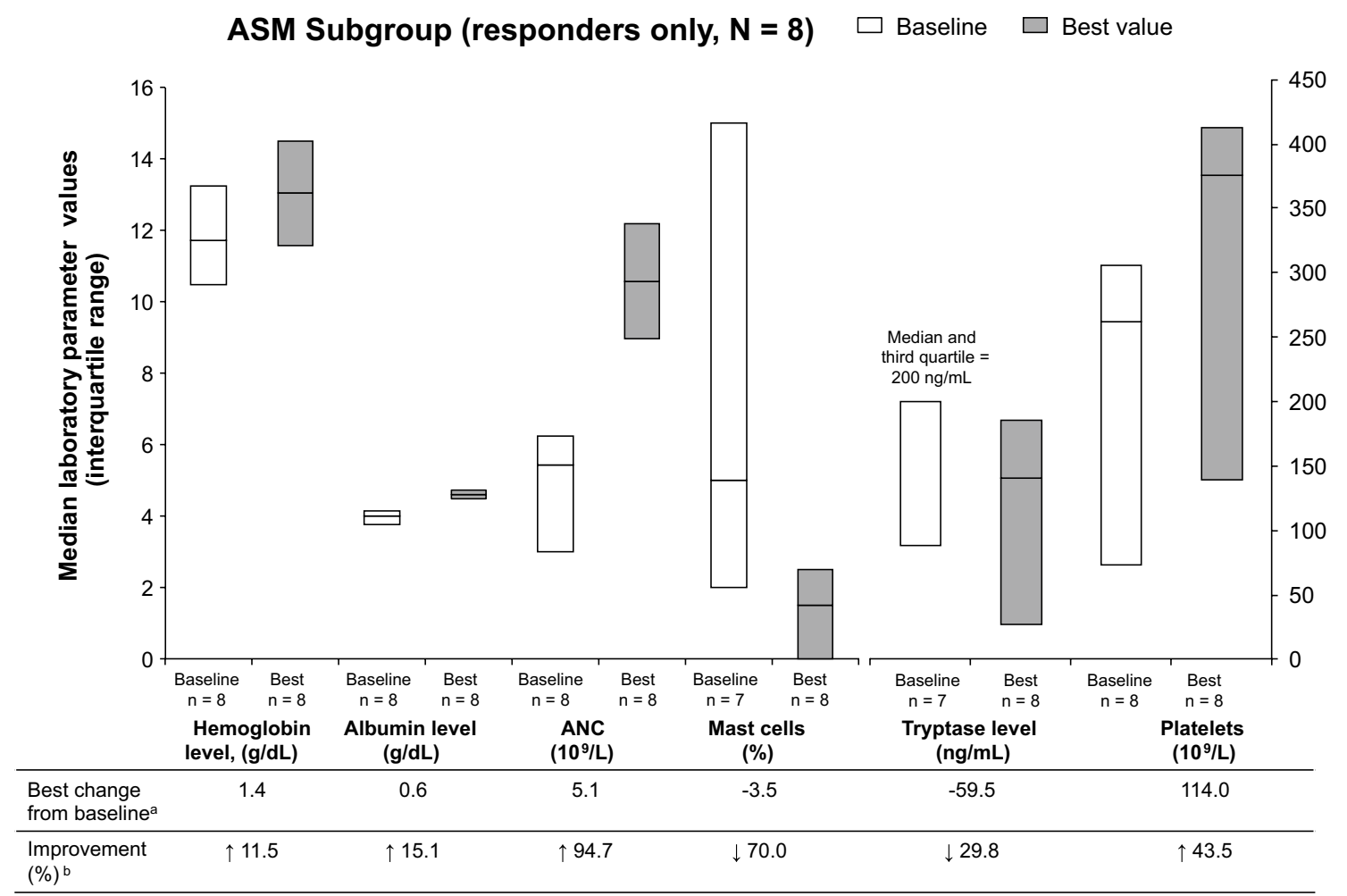

a Calculated as median best value minus median baseline value

${ }^{\mathrm{b}}$ Calculated as best change in baseline divided by median baseline value.

Fig. 1 Improvements in laboratory parameters of responders in the ASM subgroup while on study

overall safety profile for nilotinib (Kantarjian et al. 2007; Tasigna package insert. 2015). Newly occurring or worsening grade $3 / 4$ hematologic laboratory abnormalities included thrombocytopenia $(10.3 \%)$, anemia $(10.0 \%)$, and neutropenia $(6.9 \%$; Table 5$)$. The most frequent newly occurring or worsening grade 3/4 biochemical laboratory abnormalities included decreased serum phosphate $(17.2 \%)$, increased serum lipase $(17.0 \%)$, increased serum bilirubin (13.3\%), and increased serum alanine aminotransferase $(10.2 \%)$. Study drug-related SAEs of any grade were experienced by 14 patients $(23.0 \%)$. Diarrhea $(4.9 \%)$, vomiting $(3.3 \%)$, and dehydration $(3.3 \%)$ were the only study drug-related SAEs that occurred in more than 1 patient. Patients were carefully monitored for cardiac changes occurring on study. A QTcF increase $>60 \mathrm{~ms}$ from baseline occurred in two patients but did not result in treatment discontinuation in either patient. No patients had a QTcF $>480 \mathrm{~ms}$.

\section{Discussion}

$\mathrm{SM}$ is a heterogeneous disease. Consensus guidelines on the diagnosis and subclassification of patients with SM were published in 2007 (Valent et al. 2007) and have since been updated and refined by several groups, including the
WHO (Pardanani and Tefferi 2010a, b; Valent et al. 2012; Horny et al. 2008). These criteria have established definitive categories of SM distinguishable by their clinical presentation, histology, and growth characteristics: ISM, ISM with bone marrow involvement but no skin lesions, smoldering SM (SSM), SM-AHNMD, ASM, and MCL (Gotlib et al. 2013). These categories were established after the design of the current trial. Here, disease subtypes were determined retrospectively, and the study population included patients with a heterogeneous mixture of SM subtypes, making interpretation of the data difficult.

Patients with different SM subtypes require different types of treatment. Patients with ISM may not require cytoreductive therapy because their symptom burden is low (Valent et al. 2010). Traditional treatments for more advanced SM, including cladribine (Hermine et al. 2010) and IFN (Casassus et al. 2002), are sufficient to improve disease symptoms but have limited efficacy in reducing underlying disease burden (Lim et al. 2009a). Given the inadequacy of current treatment strategies, particularly with aggressive SM subtypes, and the role that KIT activation may play in the disease, the level of interest in targeted therapies for the treatment of SM has increased.

The high prevalence of the KIT D816V activating mutation in patients with SM led to the development of KIT 
ISM Subgroup (all patients, $\mathrm{N}=19$ )

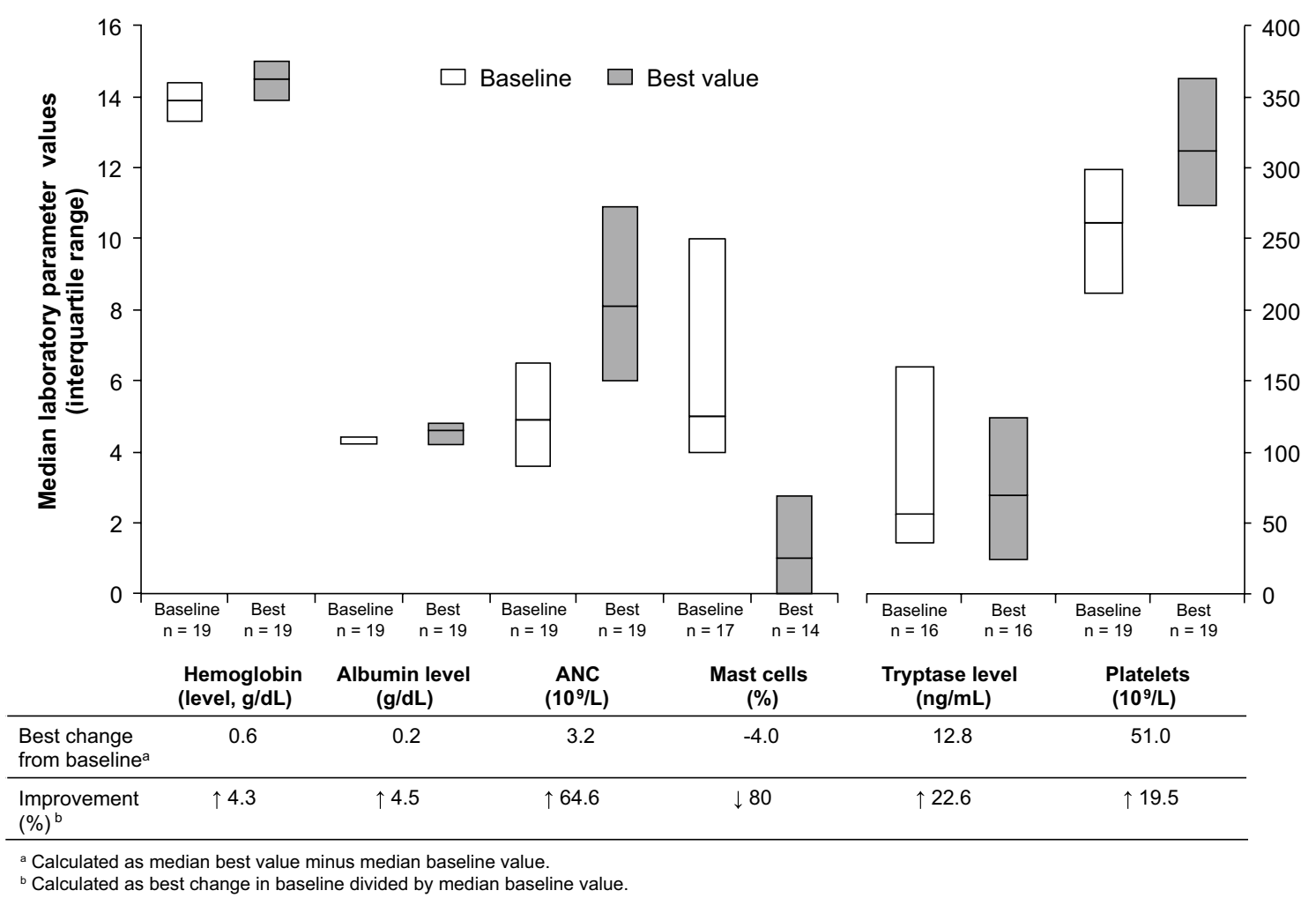

Fig. 2 Improvements in laboratory parameters in the ISM subgroup while on study

inhibitors for the treatment of this disease (Pardanani et al. 2003). Imatinib is a KIT-targeted TKI that is approved for patients with multiple hematologic malignancies, including adult patients with ASM without the KIT D816V mutation or with unknown KIT mutational status (Gleevec package insert. 2015). However, imatinib has demonstrated only modest activity against the KIT D816V mutation in vitro and in the clinic (Lim et al. 2009a; Vega-Ruiz et al. 2009; Gleixner et al. 2006). For example, a study including 22 patients with SM treated with imatinib demonstrated an ORR of $33.3 \%$ in patients without the KIT D816V mutation, $16.7 \%$ in patients with this mutation, and $0 \%$ in patients with missing mutation data (Lim et al. 2009a).

Here, we report the activity of nilotinib in patients with SM enrolled in an open-label registration trial. Patients with SM, with or without the KIT D816V mutation, met the standard disease criteria for SM and had a clinical indication for treatment. Approximately half of the patients $(47.5 \%)$ had received no prior treatment for SM. Eight patients $(21.6 \%)$ in the ASM subgroup had a minor response or better to nilotinib. The safety profile of nilotinib in patients with SM was similar to that previously reported with nilotinib in other hematologic malignancies (Kantarjian et al. 2007; Tasigna package insert. 2015).
Although nilotinib has shown little inhibitory activity toward the KIT D816V/Y mutation in vitro (von Bubnoff et al. 2005; Verstovsek et al. 2006; Manley et al. 2010), the ORR in patients with ASM with the KIT D816V mutation at any time was higher than that in patients without the mutation at baseline $[8 / 29(27.6 \%)$ vs $0 / 8(0 \%)$, respectively]. The mechanisms responsible for this are currently unknown. The D816V mutation shifts KIT from the inactive conformation, to which imatinib and nilotinib bind, to its active conformation (Gajiwala et al. 2009; Weisberg et al. 2005). Nilotinib-mediated inhibition of KIT signaling in nontransformed cells that support survival of malignant cells (e.g., stromal cells, mast cells, macrophages) may provide some clinical benefit, even in patients with KIT D816V-mutated SM (Pittoni et al. 2011). In addition, nilotinib may be active against other KIT-dependent and -independent pathways involved in the development of SM (Gleixner et al. 2011; Schwaab et al. 2013). Additional studies are needed to further explore the pathogenesis of SM and to understand the mechanisms underlying the clinical activity of nilotinib in SM. It also must be noted that 20 patients did not have KIT mutation results available at baseline. Thus, response rates in patients with mutated KIT D816V vs unmutated KIT must be interpreted with caution. 
Other Subgroup (all patients, $\mathrm{N}=5$ )

$\square$ Baseline $\square$ Best value
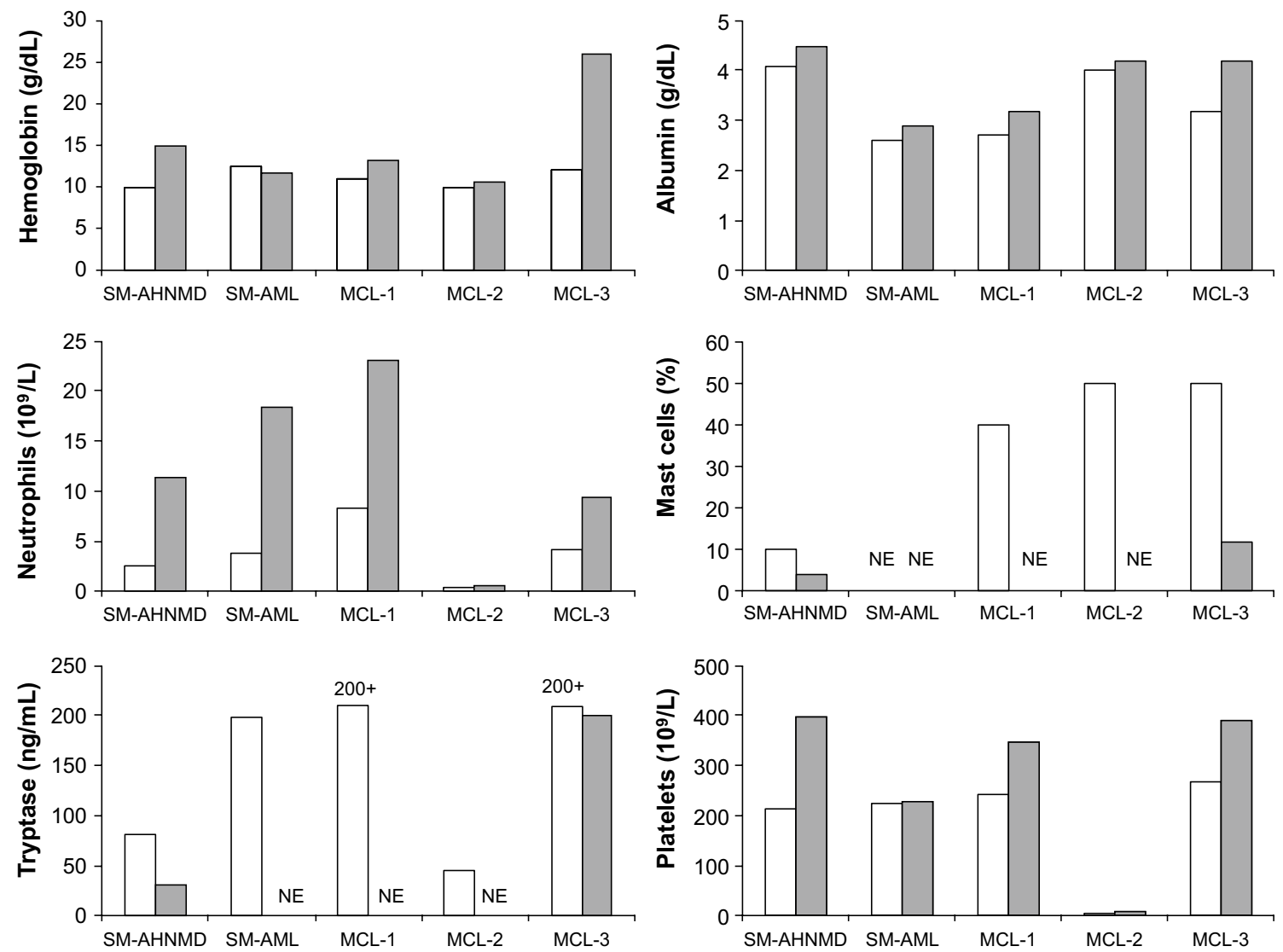

Each set of bars denotes the laboratory values for a single patient in the "other" SM subgroup. MCL-1, -2 , and -3 represent each of the 3 patients with MCL in this subgroup.

Fig. 3 Improvements in laboratory parameters for each patient in the "other" subgroup while on study

Fig. 4 Overall survival

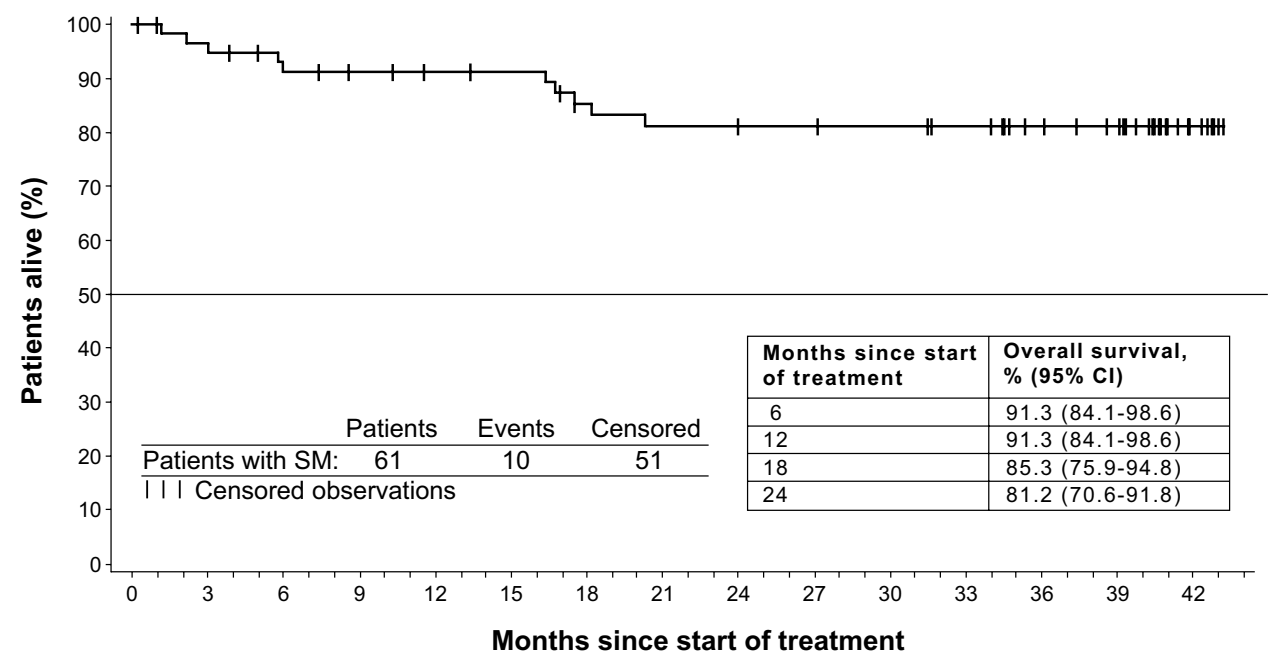

At-risk/events $61 / 0$ 
Table 4 Most common study drug-related nonhematologic AEs (occurring in $\geq 10 \%$ of patients)

\begin{tabular}{lcl}
\hline $\begin{array}{l}\text { Nonhematologic } \\
\text { AE, } n(\%)\end{array}$ & $\begin{array}{l}\text { Any grade } \\
(n=61)\end{array}$ & $\begin{array}{l}\text { Grade 3/4 } \\
(n=61)\end{array}$ \\
\hline Nausea & $24(39.3)$ & $2(3.3)$ \\
Headache & $20(32.8)$ & $3(4.9)$ \\
Fatigue & $18(29.5)$ & $1(1.6)$ \\
Diarrhea & $17(27.9)$ & $4(6.6)$ \\
Vomiting & $16(26.2)$ & $2(3.3)$ \\
Pruritus & $15(24.6)$ & $1(1.6)$ \\
Muscle spasms & $13(21.3)$ & $2(3.3)$ \\
Upper abdominal pain & $12(19.7)$ & $1(1.6)$ \\
Rash & $10(16.4)$ & $1(1.6)$ \\
Dizziness & $8(13.1)$ & $1(1.6)$ \\
Arthralgia & $7(11.5)$ & $1(1.6)$ \\
Bone pain & $7(11.5)$ & $1(1.6)$ \\
Myalgia & $7(11.5)$ & $1(1.6)$ \\
Peripheral edema & $7(11.5)$ & $1(1.6)$ \\
\hline
\end{tabular}

$A E$ adverse event

Table 5 Newly occurring or worsening grade 3/4 laboratory abnormalities (occurring in $\geq 5 \%$ of evaluable patients)

\begin{tabular}{lr}
\hline Laboratory abnormality & $n / N^{\mathrm{a}}(\%)$ \\
\hline Hematologic & \\
Thrombocytopenia & $6 / 58(10.3)$ \\
Anemia & $6 / 60(10.0)$ \\
Neutropenia & $4 / 58(6.9)$ \\
Nonhematologic & \\
Decreased serum phosphate & $10 / 58(17.2)$ \\
Increased serum lipase & $9 / 53(17.0)$ \\
Increased serum bilirubin (total) & $8 / 60(13.3)$ \\
Increased serum ALT & $6 / 59(10.2)$ \\
Decreased sodium & $4 / 60(6.7)$ \\
Hyperglycemia & $3 / 56(5.4)$ \\
Decreased serum albumin & $3 / 58(5.2)$ \\
Decreased potassium & $3 / 60(5.0)$ \\
\hline
\end{tabular}

$A E$ adverse event, $A L T$ alanine aminotransferase

${ }^{a}$ Patients evaluable postbaseline who had $<$ grade 4 at baseline

In the current study, all patients with ASM who responded met the major criterion for SM diagnosis (multifocal clusters of mast cells in the bone marrow) at baseline. During the study, the proportion of mast cells in the bone marrow in patients who responded decreased by $70.0 \%$, suggesting that nilotinib did have an effect on the underlying disease in these patients. Likewise, serum tryptase level is a minor diagnostic criterion in SM and a strong measure of disease status. Elevated serum tryptase level can predict progression to more aggressive forms of disease
(Kristensen et al. 2013) and has been shown to correlate with KIT D816V allele burden, a marker of disease severity (Matito et al. 2013). In the current study, the median tryptase level decreased by $29.8 \%$ in responders with ASM. Thus, while the rate of response was not high, the quality of response in patients who did respond suggests that nilotinib may have clinical benefit in some patients. Improvements in laboratory parameters were also observed in the ISM and the "other" subgroups. However, these subgroups cannot be evaluated using standard ASM criteria due to differences in the underlying disease.

The current trial had several limitations. Current response criteria, developed after the design of this study, are based on the resolution of $\mathrm{C}$-findings in patients with the aggressive subtype of SM (Gotlib et al. 2013). This study included patients less likely to have $\mathrm{C}$-findings at baseline; $31.1 \%$ of patients had ISM. Using C-findings as a measure of response may not be appropriate for patients with ISM. Also, because C-findings were collected retrospectively in this study, these data may not be complete. Furthermore, the minimum response duration in this study (4 weeks) was shorter than current response duration criteria (12 weeks) (Gotlib et al. 2013), which may have increased the rates of response observed. For these reasons, the true magnitude of the clinical benefit of nilotinib in this population is difficult to determine, and it is possible that the response rates observed in this study may overestimate the true benefit of nilotinib in patients with advanced SM.

Previous studies have demonstrated a median overall survival of 24 months in patients with ASM (Lim et al. 2009b; Fuller 2012). Despite a lack of response in the majority of patients in the current study, overall survival was $81.2 \%$ at 24 months, with the median survival not yet reached after a median of 34.7 months of patient followup. Thus, our data demonstrate that treatment with nilotinib may provide some clinical benefit to patients with SM. It is also possible, as our retrospective interpretation of the study population suggests, that a sufficient number of patients with ISM were included who may have skewed the overall survival results in such a manner that the true benefit is somewhat less than identified here. Additional studies will be necessary to determine whether nilotinib improves the long-term survival of patients with SM, including patients with ASM.

Several additional KIT-targeting TKIs are currently being investigated in patients with SM. Although the dual BCR-ABL/SRC TKI dasatinib inhibits the kinase activity of KIT D816V in vitro (Shah et al. 2006; Lombardo et al. 2004) and has demonstrated efficacy in other myeloproliferative neoplasms, such as CML (Kantarjian et al. 2010), it has displayed minimal activity in patients with SM (Verstovsek et al. 2008). Data from a phase 2 study in patients with systemic or cutaneous mastocytosis $(N=25)$ treated 
with the KIT/LYN kinase inhibitor masitinib, however, demonstrated an ORR of $56.0 \%$ and modest improvements in symptoms and quality-of-life measurements after 12 weeks of treatment (Paul et al. 2010).

The multikinase inhibitor midostaurin has also demonstrated potent in vitro activity against KIT D816V (Gleixner et al. 2006; Weisberg et al. 2002; Fabbro et al. 2000) as well as activity in patients with advanced SM with this mutation (Gotlib et al. 2010). Phase 2 data in a cohort of 26 patients with advanced SM demonstrated an ORR of $69.2 \%$, and the presence of the KIT D816V mutation was significantly associated with achievement of a major response (Gotlib et al. 2010). Another phase 2 study used central adjudication to identify patients with ASM or MCL, thereby producing a homogenous population of patients with advanced SM according to the current definitions (Gotlib et al. 2014). In this trial, which evaluated midostaurin in patients with ASM or MCL $(n=89)$, high rates of durable responses and good tolerability were observed. The ORR was $60 \%$ (45\% major response and $15 \%$ partial response). The ORR was $63 \%$ in patients with the KIT D816V mutation (46 of 73) and $44 \%$ in patients without it ( 7 of 16 ). With a median follow-up of 26 months, the median duration of response was 24 months (range 11 months-not evaluable), and median OS was 29 months (range 18 months-not evaluable). Further, improvements in symptoms and quality-of-life measures were observed in all patients across all reported scales.

KIT-targeting TKIs may also be effective when used in combination with other treatments, such as chemotherapy. Treatment with the TKI dasatinib and standard chemotherapy induced hematologic remission and decreased the levels of KIT D816V in the mast cells of a patient with SM-AML (Ustun et al. 2009). Combined inhibition of KIT and its downstream effectors, such as PI3K or STAT5, may also be an effective strategy in SM (Harir et al. 2008; Buet et al. 2012). Several clinical trials are evaluating additional agents in patients with SM, including the interleukin 2-diphtheria toxin fusion protein denileukin diftitox and the mechanistic target of rapamycin (mTOR) inhibitor everolimus (US National Institutes of Health 2015).

Despite its limitations, this study provides additional information about this rare disease and illustrates the importance of enrolling only patients who meet strict eligibility criteria in prospective trials to ensure consistency of populations across studies. Data from the present analysis demonstrated that nilotinib has a safety profile that is consistent with that seen in previous reports and has modest clinical activity in patients with SM, particularly patients with the KIT D816V mutations who otherwise have limited treatment options. Nilotinib, either alone or in combination with other agents, may have a role in the treatment of these patients. However, other TKIs, which in more recent trials have shown higher rates of response in patients with advanced SM, may provide more clinical benefit for patients with more aggressive disease. Future studies of SM should use the most recent disease classification definitions to generate homogeneous patient populations and more robust data sets. Furthermore, identification of SM patient subgroups mostly likely to benefit from nilotinib may be an important approach in future studies of SM.

Acknowledgments We thank Pamela Tuttle, PhD (Articulate Science, LLC), for medical editorial assistance. Financial support for medical editorial assistance was provided by Novartis Pharmaceuticals Corporation.

Conflict of interest A.H. has received research funding from Novartis Pharmaceuticals Corporation, Bristol-Meyers Squibb, Pfizer, and Ariad. M.B. acted as a consultant for Novartis Pharmaceuticals Corporation and Ariad, and received Honoria, and participated in a speaker's bureau for Ariad, Bristol-Meyers Squibb, Pfizer, and Novartis Pharmaceuticals Corporation. F.J.G. received research funding from Novartis Pharmaceuticals Corporation. P.D.lC. received honoraria from Novartis Pharmaceuticals Corporation, BMS, Pfizer, and Ariad and received research funding from Novartis Pharmaceuticals Corporation. M.C.M.: no conflicts of interest to declare. A.R. acted as a consultant and received honoraria from Novartis Pharmaceuticals Corporation. H.S. and M.L. are employees of Novartis Pharmaceuticals Corporation. S.N. is an employee and stock holder of Novartis Pharmaceuticals Corporation. H.M.K. received research funding from Novartis Pharmaceuticals Corporation, Bristol-Meyers Squibb, Pfizer, and Amgen.

Open Access This article is distributed under the terms of the Creative Commons Attribution 4.0 International License (http://creativecommons.org/licenses/by/4.0/), which permits unrestricted use, distribution, and reproduction in any medium, provided you give appropriate credit to the original author(s) and the source, provide a link to the Creative Commons license, and indicate if changes were made.

\section{References}

Akin C, Metcalfe DD (2004) The biology of Kit in disease and the application of pharmacogenetics. J Allergy Clin Immunol 114:13-19

Andersen CL, Kristensen TK, Severinsen MT et al (2012) Systemic mastocytosis—a systematic review. Dan Med J 59:A4397

Buet D, Gallais I, Lauret E et al (2012) Cotargeting signaling pathways driving survival and cell cycle circumvents resistance to kit inhibitors in leukemia. Blood 119:4228-4241

Casassus P, Caillat-Vigneron N, Martin A et al (2002) Treatment of adult systemic mastocytosis with interferon-alpha: results of a multicentre phase II trial on 20 patients. Br J Haematol 119:1090-1097

Erben P, Schwaab J, Metzgeroth G et al (2014) The KIT D816V expressed allele burden for diagnosis and disease monitoring of systemic mastocytosis. Ann Hematol 93:81-88

Fabbro D, Ruetz S, Bodis S et al (2000) PKC412 - a protein kinase inhibitor with a broad therapeutic potential. Anticancer Drug Des 15:17-28

Fuller SJ (2012) New insights into the pathogenesis, diagnosis, and management of mastocytosis. Hematol Oncol Clin North Am 26:1143-1168

Furitsu T, Tsujimura T, Tono T et al (1993) Identification of mutations in the coding sequence of the proto-oncogene c-kit in a human 
mast cell leukemia cell line causing ligand-independent activation of c-kit product. J Clin Invest 92:1736-1744

Gajiwala KS, Wu JC, Christensen J et al (2009) KIT kinase mutants show unique mechanisms of drug resistance to imatinib and sunitinib in gastrointestinal stromal tumor patients. Proc Natl Acad Sci USA 106:1542-1547

Garcia-Montero AC, Jara-Acevedo M, Teodosio C et al (2006) KIT mutation in mast cells and other bone marrow hematopoietic cell lineages in systemic mast cell disorders: a prospective study of the Spanish Network on Mastocytosis (REMA) in a series of 113 patients. Blood 108:2366-2372

Giles FJ, Kantarjian HM, le Coutre PD et al (2012) Nilotinib is effective in imatinib-resistant or -intolerant patients with chronic myeloid leukemia in blastic phase. Leukemia 26:959-962

Giles FJ, le Coutre PD, Pinilla-Ibarz J et al (2013) Nilotinib in imatinib-resistant or imatinib-intolerant patients with chronic myeloid leukemia in chronic phase: 48-month follow-up results of a phase II study. Leukemia 27:107-112

Gleevec $^{\circledR}$ (imatinib) [prescribing information] (2015) Novartis Pharmaceuticals Corporation, East Hanover

Gleixner KV, Mayerhofer M, Aichberger KJ et al (2006) PKC412 inhibits in vitro growth of neoplastic human mast cells expressing the D816V-mutated variant of KIT: comparison with AMN107, imatinib, and cladribine (2CdA) and evaluation of cooperative drug effects. Blood 107:752-759

Gleixner KV, Mayerhofer M, Cerny-Reiterer S et al (2011) KIT-D816V-independent oncogenic signaling in neoplastic cells in systemic mastocytosis: role of Lyn and Btk activation and disruption by dasatinib and bosutinib. Blood 118:1885-1898

Gotlib J, DeAngelo DJ, George TI et al (2010) KIT inhibitor midostaurin exhibits a high rate of clinically meaningful and durable responses in advanced systemic mastocytosis: report of a fully accrued phase II trial [abstract 316]. Blood 116

Gotlib J, Pardanani A, Akin C et al (2013) International Working Group-Myeloproliferative Neoplasms Research and Treatment (IWG-MRT) \& European Competence Network on Mastocytosis (ECNM) consensus response criteria in advanced systemic mastocytosis. Blood 121:2393-2401

Gotlib J, Kluin-Nelemans HC, George T et al (2014) Midostaurin (PKC412) demonstrates a high rate of durable responses in patients with advanced systemic mastocytosis: results from the fully accrued global phase 2 CPKC412D2201 trial [abstract 636]. Blood 124

Harir N, Boudot C, Friedbichler K et al (2008) Oncogenic kit controls neoplastic mast cell growth through a Stat5/PI3-kinase signaling cascade. Blood 112:2463-2473

Hermine O, Hirsh I, Damaj G et al (2010) Long term efficacy and safety of cladribine in adult systemic mastocytosis: a French multicenter study of 44 patients [abstract 1982]. Blood 116

Hochhaus A, Ottmann OG, Lauber S et al (2006) A phase II study of nilotinib, a novel inhibitor of c-kit, PDGFR, and bcr-abl, administered to patients with systemic mastocytosis [abstract 2703]. Blood 108

Horny HP, Akin C, Metcalfe DD, Escribano L, Bennett JM, Valent P (2008) Mastocytosis (mast cell disease). In: Swerdlow SH, Campo E, Harris NL et al (eds) WHO classification of tumours. International Agency for Research and Cancer (IARC) Press, Lyon, pp 54-63

Kantarjian H, Giles F, Wunderle L et al (2006) Nilotinib in imatinibresistant CML and Philadelphia chromosome-positive ALL. N Engl J Med 354:2542-2551

Kantarjian HM, Giles F, Gattermann N et al (2007) Nilotinib (formerly AMN107), a highly selective BCR-ABL tyrosine kinase inhibitor, is effective in patients with Philadelphia chromosomepositive chronic myelogenous leukemia in chronic phase following imatinib resistance and intolerance. Blood 110:3540-3546
Kantarjian H, Shah NP, Hochhaus A et al (2010) Dasatinib versus imatinib in newly diagnosed chronic-phase chronic myeloid leukemia. N Engl J Med 362:2260-2270

Kristensen T, Broesby-Olsen S, Vestergaard H, Bindslev-Jensen C, Moller MB, Hospital Mastocytosis Centre Odense University (2013) Serum tryptase correlates with the KIT D816V mutation burden in adults with indolent systemic mastocytosis. Eur J Haematol 91:106-111

Lammie A, Drobnjak M, Gerald W, Saad A, Cote R, Cordon-Cardo C (1994) Expression of c-kit and kit ligand proteins in normal human tissues. J Histochem Cytochem 42:1417-1425

le Coutre PD, Giles FJ, Hochhaus A et al (2012) Nilotinib in patients with $\mathrm{Ph}+$ chronic myeloid leukemia in accelerated phase following imatinib resistance or intolerance: 24-month follow-up results. Leukemia 26:1189-1194

Lim KH, Pardanani A, Butterfield JH, Li CY, Tefferi A (2009a) Cytoreductive therapy in 108 adults with systemic mastocytosis: outcome analysis and response prediction during treatment with interferon-alpha, hydroxyurea, imatinib mesylate or 2-chlorodeoxyadenosine. Am J Hematol 84:790-794

Lim KH, Tefferi A, Lasho TL et al (2009b) Systemic mastocytosis in 342 consecutive adults: survival studies and prognostic factors. Blood 113:5727-5736

Lombardo LJ, Lee FY, Chen P et al (2004) Discovery of N-(2-chloro6-methyl-phenyl)-2-(6-(4-(2-hydroxyethyl)-piperazin-1-yl)-2methylpyrimidin-4-ylamino)thiazole-5-carboxamide (BMS354825), a dual src/abl kinase inhibitor with potent antitumor activity in preclinical assays. J Med Chem 47:6658-6661

Manley PW, Drueckes P, Fendrich G et al (2010) Extended kinase profile and properties of the protein kinase inhibitor nilotinib. Biochim Biophys Acta 1804:445-453

Matito A, Morgado JM, Alvarez-Twose I et al (2013) Serum tryptase monitoring in indolent systemic mastocytosis: association with disease features and patient outcome. PLoS One 8:e76116

National Cancer Institute (2006) Common terminology criteria for adverse events (CTCAE), version 3.0

Orfao A, Garcia-Montero AC, Sanchez L, Escribano L, REMA (2007) Recent advances in the understanding of mastocytosis: the role of KIT mutations. Br J Haematol 138:12-30

Pardanani A (2012) Systemic mastocytosis: disease overview, pathogenesis, and treatment. Hematol Oncol Clin North Am 26:1117-1128

Pardanani A (2015) Systemic mastocytosis in adults: 2015 update on diagnosis, risk stratification, and management. Am J Hematol 90:250-262

Pardanani A, Tefferi A (2010a) A critical reappraisal of treatment response criteria in systemic mastocytosis and a proposal for revisions. Eur J Haematol 84:371-378

Pardanani A, Tefferi A (2010b) Proposal for a revised classification of systemic mastocytosis. Blood 115:2720-2721

Pardanani A, Reeder TL, Kimlinger TK et al (2003) Flt-3 and c-kit mutation studies in a spectrum of chronic myeloid disorders including systemic mast cell disease. Leuk Res 27:739-742

Paul C, Sans B, Suarez F et al (2010) Masitinib for the treatment of systemic and cutaneous mastocytosis with handicap: a phase $2 \mathrm{a}$ study. Am J Hematol 85:921-925

Pittoni P, Piconese S, Tripodo C, Colombo MP (2011) Tumor-intrinsic and -extrinsic roles of c-kit: mast cells as the primary off-target of tyrosine kinase inhibitors. Oncogene 30:757-769

Quintas-Cardama A, Jain N, Verstovsek S (2011) Advances and controversies in the diagnosis, pathogenesis, and treatment of systemic mastocytosis. Cancer 117:5439-5449

Schwaab J, Schnittger S, Sotlar K et al (2013) Comprehensive mutational profiling in advanced systemic mastocytosis. Blood 122:2460-2466

Shah NP, Lee FY, Luo R, Jiang Y, Donker M, Akin C (2006) Dasatinib (BMS-354825) inhibits KITD816V, an imatinib-resistant 
activating mutation that triggers neoplastic growth in most patients with systemic mastocytosis. Blood 108:286-291

Simon R (1989) Optimal two-stage designs for phase II clinical trials. Control Clin Trials 10:1-10

Tasigna (nilotinib) [prescribing information] (2015) Novartis Pharmaceuticals Corporation, East Hanover

Tefferi A, Vardiman JW (2008) Classification and diagnosis of myeloproliferative neoplasms: the 2008 World Health Organization criteria and point-of-care diagnostic algorithms. Leukemia 22:14-22

US National Institutes of Health (2015) ClinicalTrials.gov. Accessed 9 Mar 2015

Ustun C, Corless CL, Savage N et al (2009) Chemotherapy and dasatinib induce long-term hematologic and molecular remission in systemic mastocytosis with acute myeloid leukemia with KIT D816V. Leuk Res 33(5):735-741

Valent P, Horny HP, Escribano L et al (2001) Diagnostic criteria and classification of mastocytosis: a consensus proposal. Leuk Res 25:603-625

Valent P, Akin C, Sperr WR et al (2003) Diagnosis and treatment of systemic mastocytosis: state of the art. Br J Haematol 122:695-717

Valent P, Akin C, Escribano L et al (2007) Standards and standardization in mastocytosis: consensus statements on diagnostics, treatment recommendations and response criteria. Eur J Clin Invest $37: 435-453$

Valent P, Sperr WR, Akin C (2010) How I treat patients with advanced systemic mastocytosis. Blood 116:5812-5817

Valent P, Akin C, Arock M et al (2012) Definitions, criteria and global classification of mast cell disorders with special reference to mast cell activation syndromes: a consensus proposal. Int Arch Allergy Immunol 157:215-225

Vega-Ruiz A, Cortes JE, Sever M et al (2009) Phase II study of imatinib mesylate as therapy for patients with systemic mastocytosis. Leuk Res 33:1481-1484

Verstovsek S (2013) Advanced systemic mastocytosis: the impact of KIT mutations in diagnosis, treatment, and progression. Eur $\mathrm{J}$ Haematol 90:89-98

Verstovsek S, Akin C, Manshouri T et al (2006) Effects of AMN107, a novel aminopyrimidine tyrosine kinase inhibitor, on human mast cells bearing wild-type or mutated codon 816 c-kit. Leuk Res 30:1365-1370

Verstovsek S, Tefferi A, Cortes J et al (2008) Phase II study of dasatinib in Philadelphia chromosome-negative acute and chronic myeloid diseases, including systemic mastocytosis. Clin Cancer Res 14:3906-3915

von Bubnoff N, Gorantla SH, Kancha RK, Lordick F, Peschel C, Duyster J (2005) The systemic mastocytosis-specific activating cKit mutation D816V can be inhibited by the tyrosine kinase inhibitor AMN107. Leukemia 19:1670-1671

Weisberg E, Boulton C, Kelly LM et al (2002) Inhibition of mutant FLT3 receptors in leukemia cells by the small molecule tyrosine kinase inhibitor PKC412. Cancer Cell 1:433-443

Weisberg E, Manley PW, Breitenstein W et al (2005) Characterization of AMN107, a selective inhibitor of native and mutant Bcr-Abl. Cancer Cell 7:129-141

Woodward T (2003) Systemic mastocytosis. Curr Treat Options Gastroenterol 6:35-38 